\title{
Prática Médica: Onde se Cruzam CiênCia, Técnica e Mundo da Vida
}

\author{
Iara Maria de Almeida Souza
}

\section{Resumo}

0 presente artigo pretende abordar um aspecto da prática médica que fica velado quando tratamos a medicina simplesmente como reprodução de um modelo estabelecido pelas biociências, que tende para a dominação, o controle e a objetificação: o fato de que embora a medicina tenha caminhado no sentido de uma crescente racionalidade científica, opera nela um saber mais abrangente e resta um espaço (ainda que reduzido) para julgamento e avaliação, que a mantém ligada ao mundo da vida e à cultura. A análise do caso de um paciente atendido em um ambulatório de cardiologia do Hospital Universitário da Ufba nos fornecerá os elementos empíricos para levar adiante a discussão. Embora ela não seja um caso típico, é revelador em vários aspectos de muitas questões ligadas à prática médica que nos interessam aqui: a forma como o mundo da vida do paciente aparece nas consultas, o modelo ideal de paciente adotado pelos médicos, a construção de narrativas complementares que visam atribuir um sentido às ações que de outro modo pareceriam indecifráveis e as modulações da prática médica.

Palavras chave: relação médico paciente; prática médica; mundo da vida.

\section{Abstract}

This article intends to approach an aspect of medical practice that is hidden when medicine is merely treated as the reproduction of a model established by biosciences which tends to domination, control and objectification. Although medicine has advanced towards a growing scientific rationality, it works with a more comprehensive form of knowledge and there is still room, though limited, for judgment and evaluation, keeping it connected to the world of life and culture. The analysis of a patient's case, who was treated in a cardiology outpatient ward at the University Hospital of Ufba, will provide us with empirical elements to take the discussion further. Although it is not a typical case, it reveals many aspects of questions connected with medical practice that interest us: the way the patient represents his life in consultation, the ideal model adopted by doctors, the construction of supplementary narratives which aim at attributing meaning

${ }^{1}$ Professora do Departamento de Sociologia da UFBa, pesquisadora do ECSAS (Núcleo de Estudos em Ciências Sociais e Saúde).

Revista Mediaçōes, Londrina, v. 11, N. 2, p. 9-28, Jul./Dez. 2006 
to actions that would otherwise appear undecipherable, and the modulations of medical practice.

Keywords: doctor-patient relationship, medical practice, world of life.

\section{INTRODUÇÃO}

famosa frase de Hipócrates diz "a vida é breve, mas extensa é a arte".
Seria o caso de perguntarmos hoje o quanto resta de arte na medicina?
Não teria acontecido de a vida a prática médica perdeu em qualidade artística? De fato parece haver um consenso em torno da idéia de que a medicina se converte cada vez mais em uma disciplina técnica e científica e que se isso trouxe ganhos inestimáveis em termos das possibilidades de controle de enfermidades, de prolongamento da vida e diminuição da dor, provocou também uma séria atrofia na sua dimensão relacional.

A medicina que pode ser chamada de técnica científica teria logrado esse status ao se distanciar do mundo da vida cotidiana. Para aqueles mais próximos de uma visão cientificista (em sua versão mais ingênua) essa é a razão de seu extraordinário desenvolvimento, assim como se deu em outras áreas de ciência, a libertação de preconceitos e a atitude crítica frente a falsas verdades do senso comum conduziram a uma redefinição do mundo, do conhecimento e das práticas fundadas nas ciências. Para outros mais céticos com relação ao poder da ciência - que apontam para a sua dimensão de dominação e controle sobre os corpos e a vida e para os riscos trazidos pelo desenvolvimento tecnológico - esse afastamento não apenas representa algo indesejável na medida em que destitui pacientes e médicos de sua humanidade como conduz a fracassos na condução de processos de tratamento na medida em que impede 0 estabelecimento de um diálogo mais autêntico entre os dois.

Nas ciências sociais quando se trata da análise da prática médica e da relação médico-paciente essa última visão é a que parece predominar. Nas variadas linhas de argumentação ora a ênfase é posta na questão do poder profissional (que às vezes confunde-se a dominação de classe e gênero), ora no controle que a medicina e um certo ideal de saúde exercem sobre a vida dos indivíduos, e, por último, mas não menos importante, temos aqueles que apontam a objetificação que é imposta aos envolvidos na relação terapêutica (MARTINS, 2003; CAPRARA; LINS E SILVA, 1999; KOIFMAN, 2001; ACIOLE, 2004; SCHERER; MARINO; RAMOS, 2005; MARTINS, 2004).

Gostaria aqui de mudar um pouco o foco da questão e explorar algo que fica velado quando tratamos a medicina simplesmente como reprodução de um modelo estabelecido pelas biociências, que tende para a dominação, o controle e a objetificação: 
o fato de que embora a medicina tenha caminhado no sentido de uma crescente racionalidade científica, ainda opera nela um saber mais abrangente e resta um espaço (ainda que reduzido) para julgamento e avaliação, que a mantém ligada ao mundo da vida. Pretendo, portanto, atentar para aquilo que Schutz (1979) - seguindo as pegadas de Husserl - já havia observado: o fato de que qualquer província específica de significado só se descola imperfeitamente do mundo da vida, que permanece sendo o solo sobre o qual se assenta qualquer possibilidade de conhecimento científico, embora este permaneça implícito e não elaborado.

Para discutir essa questão, primeiro pretendo expor de modo muito resumido algumas vertentes de reflexão produzidas no âmbito das ciências sociais sobre a medicina, me concentrando principalmente no pensamento de Mishler (1984). A escolha desse autor se justifica na medida em que sua análise detalhada da conversação entre médico e paciente não se limita a reafirmar a assimetria de poder aí existente, mas propõe uma releitura radical da consulta de modo a colocar no centro a voz do mundo vivido do paciente, interrompida e fragmentada na consulta, mas que pode ser ouvida se realizamos um exercício de interpretação, visando recuperar aquilo que permanece oculto quando nos concentramos exclusivamente na voz da medicina (MISHLER, 1984).

Entretanto, não pretendemos nesse artigo tratar apenas do conflito entre as duas vozes, a da medicina e do mundo da vida, pois se nos ativermos a esse tema, estaremos apenas e mais uma vez atestando a distância, aparentemente incomensurável, entre dois domínios em disputa e não chegaremos à questão mencionada antes: qual o espaço na clínica para uma compreensão prática que não se reduz a aplicação direta de conhecimento biomédico? Para responder a essa pergunta é necessário avançar um pouco mais. É preciso que não nos deixemos aprisionar na armadilha das diferenças sem nenhuma medida comum, para trazer à luz a existência de um horizonte de valores e concepções ligadas ao mundo vivido que não estão ausentes da consulta, embora não sejam tematizadas, nem explicitadas.

Isso nos conduz a uma outra questão: se estamos falando de prática médica como algo que envolve uma interpretação cujas peças em jogo não estão explicitadas e nem são plenamente explicitáveis, como analisar o que se situa nesse campo dos pressupostos. Pretender lidar como esse domínio envolve um esforço para reconstituir e elucidar significados que não se apresentam diretamente e, portanto, exigem um deciframento do que está latente e implícito naquilo que é pronunciado explicitamente. Momentos de ruptura - quando o desconcerto se apresenta e interrompe a cena que parecia transcorrer de modo previsível - representam uma via aberta a esse âmbito de 
sentido, pois são situações privilegiadas para observarmos as antecipações, expectativas e padrões supostos implícitos que se desnudam justamente quando são rompidos.

Para tratarmos da questão proposta aqui: a relação entre a medicina e o mundo da vida vamos nos voltar para o caso de um paciente, José Antônio, atendido em um ambulatório de cardiologia do Hospital Universitário da UFBa. Ele não é um caso típico, se por isso entendemos algo mediano, mas é revelador em vários aspectos de muitas questões ligadas à prática médica que nos interessam aqui: a forma como o mundo da vida do paciente aparece nas consultas, às tentativas de monitorar seu comportamento, o modelo ideal de paciente adotado pelos médicos, a construção de narrativas complementares que visam atribuir um sentido às ações que de outro modo pareceriam indecifráveis e as modulações da prática médica. Mas antes de iniciarmos a narrativa do caso em questão vamos apresentar alguns breves comentários acerca da literatura sobre o tema e descrever ligeiramente o contexto em que a pesquisa foi realizada.

\section{Breves Considerações Teóricas}

Desde que Parsons (1965) trouxe o tema do papel do médico e da relação médicopaciente para o campo da sociologia essa questão tem sido explorada a partir de vários pontos de vista, não raramente em uma perspectiva de crítica à versão parsoniana considerada por demais harmoniosa, posto que enfatiza a cooperação e a complementaridade de papéis entre médico e paciente, e por isso, argumenta-se, não permite que se perceba o caráter essencialmente conflituoso das relações que têm lugar no espaço clínico. Para Freidson (1970), por exemplo, o momento da consulta é permeado por conflitos de interesses, ao invés de um acordo mútuo. Trabalhando com a noção de sistema leigo de referência - um corpo de conhecimento, crenças e ações, através do qual a doença é definida pelos diversos grupos sociais - ele aborda as diferenças existentes entre as concepções do leigo e do médico e explicita a idéia de que a construção social da doença implica uma relação assimétrica de poder entre médico e paciente, reflexo de uma dominação profissional.

Há, por outro lado, abordagens que acentuam não a dominação profissional, mas argumentam que o encontro clínico espelha a própria estrutura de dominação de classes da sociedade. A relação diferencial de poder existente entre médico e paciente nessa concepção é pensada como reflexo do domínio de uma classe sobre outra e a distância entre os dois potencializa a dominação médica e a subjugação do paciente (BOLTANSKI, 1989). Haveria ainda uma barreira lingüística separando o médico do paciente de classe trabalhadora, que é acentuada pelo uso do jargão médico, disso decorre uma diferenciação em termos do tipo de explicação que é fornecido pelo médico 
ao paciente de acordo com a classe, para a classe popular são dadas ordens e não argumentos. Apoiada em Boltanski (1989) afirma que as relações de dominação e submissão na prática médica são interpretadas como algo que tem por função "assegurar a perpetuação do modo de produção capitalista em uma determinada sociedade, através da conservação-reparação da força de trabalho" (GOULART, 1998, p. 18). Ao mesmo tempo o autoritarismo do médico para com os pacientes de classes trabalhadoras, negros e mulheres visam "promover a aquiescência como um sistema social baseado na desigualdade de poder" (p. 18).

Em continuidade com essa interpretação alguns autores apontam para o papel da medicina como instrumento de ocultamento das determinações políticas e econômicas da doença ao torná-la um evento individual, e ao fazer assim, sustenta o status quo do capitalismo que leva ao adoecimento, mas também a uma distribuição desigual das doenças e dos recursos médicos. 0 enraizamento das doenças na estrutura social é encoberto, e a responsabilidade é atribuída ao indivíduo que não tem um estilo de vida saudável, que não segue as recomendações. Portanto, a medicina despolitiza, legitima e reproduz a estrutura de classes da sociedade e o sistema econômico (WAITZKIN, 1991; FERNANDES, 1993). Há também estudos que apontam para as relações entre a medicina tecnológica e o mercado. Por exemplo, argumenta-se que os interesses do capital insuflam a produção e o uso de tecnologia e acabam por transformar médicos e pacientes em insumos na produção - algo que atrofia seriamente a dimensão cuidadora da medicina (MERHY, 2000).

As análises de Foucault ou interpretações baseadas em suas idéias criticam a simplificação da concepção marxista, que trata o poder existente na relação médicopaciente como algo que está nas mãos de um soberano - o médico, como representante de uma classe. Para eles o poder não tem um centro, é algo de natureza mais difusa, que não se faz presente apenas na punição e na interdição, mas nas formas positivas, no acordo e na gratificação. Assim o discurso médico, centrado na necessidade de adoção de um padrão de comportamento tido como racional e saudável, é visto como uma força importante na tendência contemporânea para a normatização da vida e constituição de sujeitos e corpos dóceis. A medicina e a psiquiatria são mostradas como importantes instituições disciplinares da nossa sociedade, como agências que estendem a sujeição e o controle aos mais íntimos aspectos de nossa existência. (FOUCAULT, 1987; ARMSTRONG, 1977, MARTINS, 2004).

Mishler (1984) é um autor que também adota uma posição de crítica à biomedicina e toca na questão da assimetria de poder entre os participantes no encontro clínico, mas, ao contrário de análises marcadas por generalizações acerca do mundo contemporâneo com suas tensões e tendências descrito em termos macro-sociais, ele

Prática Médica: Onde se Cruzam Crência, Técnica e Mundo da Vida 
constrói sua argumentação a partir de um exame detalhado da conversação entre médico e paciente. A entrevista médica merece essa atenção porque ela é, para Mishler, uma forma de discurso denominada de conversa significativa: não é mera fala, mas trabalho que médico e paciente realizam em conjunto e que se constitui em um componente essencial da clínica. Em sua análise ele atenta para os aspectos formais da conversação - a sucessão de perguntas e respostas, interrupções, pausas, iniciativa nas mudanças de tópico, falta de atenção para com os tópicos propostos pelo paciente - com o objetivo de mostrar o forte controle do médico sobre a consulta. Na comunicação face a face entre médico e paciente, diz ele, certos enquadramentos - institucionais - prevalecem sobre outros e a conversa que deriva das preocupações médicas encobre uma conversa mais pessoal trazida pelo paciente.

Contudo, o argumento de Mishler não se encerra aí. Ao mesmo tempo em que ele aponta para a existência de uma estrutura básica da consulta que é padronizada, ele ressalta também a resistência de alguns pacientes ao enquadramento proposto pelo médico, algo que se revela na tentativa, quase sempre frustrada, de introduzir temas de seu mundo da vida, tópicos que logo são silenciados pela desatenção ou interrupção do médico. Assim, ele propõe que na análise cabe ao cientista social resgatar essa conversa mais pessoal trazida pelo paciente e que foi, provavelmente, fragmentada e negligenciada pelo médico. Caso contrário, argumenta, estaremos também de um ponto de vista analítico reforçando a assimetria de poder existente.

0 marcado predomínio da voz da medicina sobre a voz do mundo da vida na consulta é relacionado por Mishler a certas tendências presentes na vida social contemporânea. Seu argumento - pautado na teoria de Habermas da ação comunicativa - é de que a luta entre dois diferentes tipos de racionalidade, a instrumental e a comunicativa, se expressa no encontro clínico e toma a forma de um conflito entre a voz da medicina, representante da racionalidade instrumental, e a voz do mundo da vida do paciente, situado no âmbito da racionalidade comunicativa, orientada por valores e considerações morais. 0 domínio da voz da medicina durante a consulta revela 0 processo de colonização do mundo da vida que é invadido pela racionalidade instrumental, aquela presente na atitude científica, em que são usadas regras abstratas e em que o contexto é extirpado da cena, a ação é orientada para a obtenção de fins e os meios são definidos por considerações técnicas, antes que valorativas.

Um dos problemas com a concepção de Mishler, como apontam Barry et al. (2001), é que ele acaba por ser excessivamente crítica para com a medicina, pois, praticamente descarta a possibilidade de existência de qualquer pretensão moral por parte do médico. E, além disso, a despeito de sustentar a idéia de que há um entendimento 
possível entre a medicina e o mundo da vida, ele acaba por situar essas duas esferas em âmbitos opostos, sem atentar para o fato de que, a despeito do predomínio da voz da medicina, esses dois mundos estão continuamente em comunicação. Por um lado, o esquema de conhecimento usado cotidianamente pelos pacientes modifica-se a partir do encontro médico. Por outro lado, a medicina, assim como outras ciências, está assentada em certas concepções morais sobre o homem, a vida, que não são em sentido estrito nem técnicas, nem científicas. Há autores que já apontam para questões próximas a essas, como Schreiber (1997) que explora a dimensão artística da medicina, ou Bonet (2004) quando trata das emoções na prática médica e Menezes (2001) que aborda as dificuldades de certas decisões éticas dos médicos. Diferente desses autores, pretendo chamar a atenção para o entrelace entre voz da medicina e mundo da vida, tema que será abordado aqui a partir da análise do caso de um paciente em tratamento em um ambulatório de cardiologia, mas antes de fazê-lo, descreverei rapidamente qual era 0 contexto de atendimento em que pude gravar as consultas do paciente e observar as reações de médicos e estudantes ao seu estilo de conduta.

\section{O Ambulatório de Cardiologia}

0 relato do caso que apresentado aqui é parte do material de pesquisa coletada para a elaboração de minha tese de doutorado. É resultado de um trabalho de campo que durou dois anos e envolveu a gravação de consultas e entrevistas, interação com pacientes na sala de espera e observação de discussões de caso e de diálogos informais na preceptoria entre médicos e estudantes de medicina. 0 locus da pesquisa é um ambulatório de cardiologia do Hospital das Clínicas da UFBa, mantido pela Fundação Baiana de Cardiologia (FBC): Ambulatório de Cardiopatia Isquêmica e Dislipidemia - ACID, sigla com a qual me referirei e ele doravante. Os pacientes atendidos aí, cerca de 1000 pessoas, entre homens e mulheres, em sua maioria têm idade acima de 50 anos e são de classe trabalhadora. Um número considerável deles, além de sofrer das doenças mencionadas no nome do ambulatório, também padecia de diabetes e hipertensão.

No hospital o espaço reservado ao ambulatório, emprestado pela Fisioterapia, era bastante precário e estava dividido em 3 salas, nas quais funcionavam 6 "consultórios", separados uns dos outros por biombos feitos de lençóis. Havia uma pequena sala separada que era usada como local de organização dos trabalhos e como preceptoria, aí estudantes, residentes e preceptores discutiam entre si os casos, enquanto os pacientes aguardavam nos "consultórios" as deliberações sobre a condução do tratamento. Era nessa sala pequena, quente e frequentemente com mais pessoas do 
que seria razoável, o lugar onde eu costumava ficar prestando atenção às discussões de caso e a conversas mais descontraídas entre estudantes, preceptores e residentes.

0 ACID funcionava todas as segundas e quartas-feiras à tarde, das 13 às 18 horas. Cerca de 20 pacientes eram atendidos em cada turno de trabalho. A equipe de trabalho do ambulatório era constituída de três preceptores (dois estavam sempre presentes simultaneamente), dois residentes em cardiologia, que atuavam como auxiliares dos preceptores, e 12 internos, estudantes de terceiro e quarto, que se revezavam a cada tarde em grupos de 6 . Estes atendiam os pacientes, apresentavam os casos aos preceptores, escreviam receitas e formulários de solicitação de exames, registravam a consulta em prontuário, realizavam ainda algumas tarefas ligadas à organização do trabalho e freqüentavam as sessões didáticas semanais sobre temas como dislipidemias, hipertensão, diabetes, até coisa mais prosaica como o custo dos medicamentos e as alternativas de remédios mais baratas.

Em geral, o esquema de atendimento no ACID era o seguinte, o estudante chegava por volta das 13 horas, já encontrava lá a agenda com a lista dos pacientes, seus prontuários e fichas empilhados por ordem de chegada. Cada um procurava um dos "consultórios" disponíveis para se estabelecer. Uma vez acomodados, estudavam 0 prontuário do paciente e tinha início a consulta, ou melhor, a sua primeira fase, aquela em que eles colhiam a história médica e as queixas dos pacientes, viam resultados de exames e faziam eles mesmos o exame físico: verificação da pressão arterial e o do pulso, ausculta, apalpação, tomada de medida da cintura e do quadril. Depois disso, os pacientes ficavam na sala de atendimento, enquanto o interno saía para expor o caso aos preceptores. Após a discussão, no retorno o estudante trazia uma a receita e a solicitação de exames. 0 tempo de consulta, incluindo aí o intervalo da discussão de caso, girava em torno de uma hora.

Na discussão do caso, o interno apresenta ao preceptor uma história de doença, em uma sequiência padronizada: narra os antecedentes do caso (tempo e condição "objetiva" do coração e artérias cardíacas), os sintomas atuais ou sua ausência, resultado de exames e tratamento em curso. A esse conjunto de informações encadeadas deve proceder uma deliberação do preceptor acerca do que deve ser feito doravante com 0 paciente: manter os medicamentos ou trocá-los, solicitar novos exames ou só os de rotina? Usualmente são essas as questões às quais o médico deve responder ao final de uma apresentação de caso. Daí então o estudante volta ao seu paciente levando a conclusão médica sobre o seu caso. 0 que se espera do paciente é que ele coopere com o médico, conduza de modo apropriado o tratamento e não tente receber do médico mais do que ele pode oferecer: conhecimento e cuidados com a saúde. Mas nem sempre é assim, o inesperado sempre irrompe sob a forma de um paciente pouco dado a se 
conformar com as expectativas médicas. 0 caso que veremos em seguida é um desses pacientes-problema, que justamente por serem pouco afeitos a se ajustar às expectativas acabam por revelar supostos implícitos da prática médica, as diferentes formas de responder ao inusitado e a construção de narrativas complementares para tentar dar conta e fazer sentido das ações que parecem destoar do padrão esperado.

\section{O Caso José Antônio}

José Antônio é um homem de 53 anos, usa óculos de lentes grossas e se veste de um modo mais formal do que é usual entre os pacientes do ambulatório: camisa de manga cumprida abotoada, mesmo em pleno verão. Antes de conversar com ele pela primeira vez, já o conhecia, ou melhor, já ouvira várias conversas de médicos e estudantes sobre ele, um paciente incomum. 0 que o tornava assim tão distinto? Primeiro, embora não o mais importante, ele era conhecido de gerações de estudantes por apresentar uma lesão rara nas mãos, causada pelos níveis excessivamente altos de colesterol (a hipercolesterolemia - nível elevado de colesterol no sangue - é uma doença quase invisível, porque usualmente não produz sinais aparentes ou sintomas claramente manifestos). Assim, não era inusitado vê-lo cercado por estudantes que desejavam ver esse fenômeno, que ele exibia sem constrangimento e talvez até com certo gosto e orgulho de quem possui uma característica excepcional e apreciada.

Além disso, ele padecia de doença cardíaca grave e diabetes fora de controle. Suas taxas de glicemia e de gordura no sangue eram tão elevadas que suscitavam os seguintes comentários dos médicos: "Tem tanta gordura que dá para fritar um ovo no sangue desse cara", "o sangue dele parece leite condensado". 0 que é notável no caso de José Antônio, entretanto, não são apenas os aspectos médicos do caso, sua própria personalidade parece intrigar e incomodar as pessoas: Qualquer interno que se encarregue de atendê-lo antes de iniciar a consulta é advertido pela preceptora ou por algum estudante mais antigo: seu problema cardíaco é muito sério, a despeito disso, não segue as recomendações do tratamento, já foi internado várias vezes com crise de hiperglicemia por ter deixado de usar a insulina. É descrito como "rebelde", "carente", "queixoso", "deixa de tomar os remédios para ter novas crises e chamar a atenção da família, que não cuida mesmo dele", ainda assim é digno de compaixão por conta da extrema gravidade de seu caso e de sua pobreza. Aqui já vemos um dos nossos temas, a prática clínica não é pura aplicação de ciência e técnica a um paciente objetificado em um contexto neutro. José Antônio, por ser alguém com tantas peculiaridades, acaba por se tornar, para os que o atendem, bem mais do que um corpo despersonalizado, éportador de uma lesão, mas também alguém com uma história, um contexto familiar, motivos 
para agir, e um paciente que solicita dos médicos mais do que eles estão acostumados a oferecer.

As respostas que ele provoca nas pessoas, entretanto, não são exatamente homogêneas, há os que tentam ajudá-lo de muitas formas com aconselhamento, advertência, doação de remédios e os que preferem tentar extrair das inúmeras queixas que ele apresenta aquilo que realmente tem um "substrato real", desprezando o que é "fantasia" para chamar a atenção. As duas atitudes convivem, inclusive em uma mesma consulta. Ou seja, há os médicos que são mais permeáveis a entrada do mundo da vida do paciente na medicina, por razões que têm a ver com sua sensibilidade, valores, experiências distintas de aprendizado e há os que se mostram mais resistentes a intrusão de temas não propostos por eles e às tentativas do paciente de envolvê-los em sua trama. Tal atitude, apesar de distinta, pode ser remetida também a um padrão valorativo, modalidades de sensibilidade e sedimentação de um saber. Veremos como essas modulações da prática médica revelam-se em uma mesma consulta.

José Antônio começa sendo atendido por uma estudante, Roqueline. Ela já 0 atendeu antes, conhece suas histórias e queixas. Por isso procura ser bastante didática com ele acerca do uso de medicamentos, do risco da hipoglicemia, ao mesmo tempo em que, entre uma pergunta e outra sobre os cuidados que ele deve ter para consigo, insere reprimendas e censuras aos "malucos" que deixam de tomar seus remédios.

Roqueline: Isso, o senhor tomou certinho sete dias?

José Antônio: É tomei.

Roqueline: Melhorou?

José Antônio: Melhorou, melhorou, eu senti falta foi de mais remédio né, se tivesse outra caixa. Porque melhorou.

Roqueline: Mas...Certo. É que aquele remédio ele é próprio pra infecção aí toma por um tempo limitado, o normal é que o sintoma, tudo que o Senhor tava sentindo passe. (...) Tem remédio que a gente tem que tomar a vida toda, como remédio pra tensão, remédio pra diabetes, tem que tomar a vida toda, mas tem remédio que pra controlar os bichinhos que ficam dentro da gente, que a gente mata os bichos e não precisa mais usar.

(...)

Roqueline: A insulina obvio, né?

José Antônio: E 0, a insulina não pode deixar de tomar nunca ${ }^{12}$.

Roqueline: Óbvio, é porque tem uns malucos que param.

Roqueline: Então tá tomando tudo certinho?

(..) 
José Antônio: É, é.

Roqueline: Que o senhor não é louco.

José Antônio: Tô bem melhor, Ave Maria! Eu é que sei o que já passei.

Roqueline: É porque tem uns pacientes que são malucos.

A estudante que atende José Antônio tem uma preocupação quase excessiva em ser didática, explica a diferença entre os modos de uso de medicamentos, ao fazer isso usa um vocabulário e um estilo que, supostamente, torna o entendimento mais fácil para o paciente, quando diz, por exemplo, que o remédio "mata os bichinhos dentro da gente". Além disso, é possível no fragmento acima observar também o tom de censura moral usado para falar dos "malucos" que não se cuidam. Uma interpretação foucaultiana diria que esse trecho mostra com clareza que o poder não se exerce apenas em uma modalidade negativa: a proibição e a contenção. Ao contrário, ele revela sua face também nas tentativas de persuasão, na busca de acordo positivo, no controle e na imposição de cuidados para consigo, que implica, ao fim e ao cabo, em uma destituição do paciente de seu direito sobre o seu corpo, direito de "viver, adoecer e morrer do modo que mais the aprouver" (MARTINS, 2004).

Há, contudo, algo mais revelado aí, o paciente que deve ser persuadido e que é avaliado do ponto de vista moral, é julgado de acordo com um padrão que está presente na medicina, mas que não é de modo nenhum matéria de ciência e de intervenção técnica. Anorma que prescreve que uma pessoa adulta, portadora de uma doença crônica deve assumir a responsabilidade e o empenho de cuidar de si, não emerge do conhecimento científico, mas é uma expectativa, frequentemente implícita, da medicina que advém de seus vínculos com a cultura, com valores dos quais ela se acha impregnada. Vemos que nela não opera simplesmente uma racionalidade instrumental, mas também valorativa, embora isso não implique necessariamente em afirmar uma simetria entre medicina e mundo da vida.

Voltando ao caso e à consulta, vale a pena mencionar que o remédio para infecção, ao qual a médica se refere no início do segmento de conversa acima, foi cedido a ele pelo ambulatório. A doação desse medicamento específico exigiu uma complexa operação que envolveu praticamente todos os médicos presentes. Primeiro não havia amostras disponíveis no ambulatório. Os médicos mobilizaram representantes farmacêuticos com os quais tinham uma relação mais próxima para tentar obter 0 remédio. Várias ligações de celular depois e as amostras foram conseguidas, mas só estariam disponíveis no dia seguinte. Novo problema: quem estaria lá para entregar os medicamentos a José? Lembremos que o ambulatório só funcionava duas vezes por semana. Um dos residentes que estaria de plantão se pôs a disposição para receber o 
remédio e entregá-lo ao paciente. Solucionado esse problema, restava ainda um outro: José não tinha o dinheiro do transporte para voltar ao ambulatório, sua última reserva fora com a vinda a essa consulta. 0 que fazer? Durante 0 atendimento isso foi tematizado em uma conversa entre doutora Liala, a preceptora, Roqueline, e o paciente. A primeira, Dra. Liala, teria dado o dinheiro se tivesse, mas não era o caso. Roqueline também não pôde ajudá-lo e se inquietava com isso, para ela essa era uma questão que provocava dúvidas que iam além do caso específico. Por um lado, para ela, fazer caridade não é o modo correto de se relacionar com o paciente, por outro, a demasiada pobreza de José, aliada ao modo dramático como ele falava sobre isso (ele dissera que vender um rim, possibilidade que estava considerando, era a única saída para seus problemas financeiros) despertavam nela um forte sentimento de impotência.

Roqueline: (...) Impotência, né? Isso marca, a sensação de impotência de não saber o que fazer foi com Seu José, né? Com aquela história de que ia, que queria vender o rim, e que só me deu vontade de chorar, né? (Risos) É que eu não sabia o que fazer. Tem coisa assim que eu não consigo dar às vezes 0 apoio que eu poderia dar, e me choca tanto que eu fiquei estatelada naquele dia. (Entrevistadora: De Seu José?) De Seu José que ele falou que, né? Que falou que queria vender o rim pra comprar uma casa, não sei 0 quê?

Entrevistador: E cê disse o quê pra ele?

Roqueline: Poxa, deixa eu me lembrar. Você não lembra que eu fiquei quase chorando? (...) Eu não sei o que foi que eu falei, acho que Dra. Liala tava na sala e depois eu falei muita pouca coisa, eu não consegui dar o apoio, eu fiquei totalmente impotente, não sabia o que dizer. Nem tudo a gente sabe o que dizer, isso é uma experiência assim que a gente tem que adquirir.

A pobreza extrema de José Antônio não podia ser abolida ou ignorada no trabalho médico, o mundo da vida do paciente acaba se constituindo em elemento de consideração e de deliberação dos médicos. Se em outros casos as condições materiais dos pacientes apenas se insinuavam nas consultas, no caso dele a penúria na qual vivia irrompia no cenário e frequentemente roubava a cena de sua condição clínica - que era bastante delicada também. Tal fato não decorria simplesmente, vamos dizer assim, da sua situação objetiva, mas de certo senso dramático que ele possuía. Provavelmente ele percebia 0 efeito que provocava na estudante que 0 atendia, efeito que tentou reproduzir nas consultas subseqüentes sempre lembrando que colocaria seu rim à venda. Contudo, nem todos eram afetados do mesmo modo pelas atitudes desse paciente. Um outro médico o considerava queixoso e excessivamente carente (em todos os sentidos) e procurava não estimular as lamentações. Outros ainda, a despeito de reconhecerem 0 
quanto havia de tentativa de manipulação em suas narrativas tristes, avaliavam que ele padecia verdadeiramente de inúmeras aflições e levavam isso em conta ao atendê10. De qualquer modo ninguém permanecia imune aos seus problemas, todos tinham que responder a ele de algum modo. Graças a sua obstinação e ao seu apelo dramático José Antônio força a entrada de seu mundo da vida na discussão médica. Não temos aqui uma clara separação, como quer Mishler, entre a voz da medicina e a voz do mundo. Mas é preciso observar mais detalhadamente em que termos é que se dá esse (des)encontro.

Veremos isso com mais clareza quando examinarmos o modo como Roqueline e Dr. Vivaldo, o preceptor, respondiam a queixas mais propriamente médicas: dor de cabeça, insônia e indisposição. Desde o princípio da consulta, José insistia em uma queixa de dor de cabeça muito forte que aparecia diariamente. A médica questiona 0 sintoma no intuito de esclarecer a sua origem. Nesse momento ele traz a sua interpretação do problema: são as preocupações com os filhos, suas dificuldades, as brigas entre eles que provocam seu mal estar. Roqueline, que já conhece a história, deixa-o falar sobre suas aflições. Ela o encoraja e consola, mas a despeito disso, não faz qualquer referência à relação estabelecida por José entre os problemas com os filhos e as dores de cabeça. Dar permissão ao paciente para falar, sem, contudo, retomar em seu turno a interpretação proposta por ele, quer seja para negar ou confirmar, é um dos modos apontados por Mishler da medicina desconsiderar o mundo da vida do paciente. É como se a voz do paciente caísse em um vazio e não ressoasse em lugar algum.

Há ainda um tipo curioso de variação dessa modalidade de indiferença para com aquilo que o paciente diz, que envolve por parte da médica um esforço de introduzir na conversa questões mais cotidianas, porém dando a elas um sentido bem distinto daquele dado pelo paciente.

Roqueline: Você tá assim com a mesma disposição pra ir pra igreja ou tá tendo dificuldade pra poder fazer as mesmas atividades que você sempre fez? Cê tá com 0 mesmo ânimo a mesma disposição pra poder fazer as coisas que você sempre fazia ou tá tendo alguma dificuldade?

José Antônio: Ah, a dificuldade que eu tenho é devido é... a dor nas pernas, entendeu? Porque aonde eu moro tem sessenta degraus e tem mais uma ladeira, então eu venho sentindo... às vezes eu penso que é a circulação, porque observe que eu tava olhando outro dia na perna algumas partes da perna, que não tinha ficado aquele bolinho.

José havia manifestado ter pouco desejo de sair de casa. A médica explora mais esse tema (pergunta sobre as idas a igreja e as atividades de sempre) tentando extrair 
daí uma motivação de ordem psicológica para essa conduta, enquanto ele atribui às complicações relativas a sua condição física e ao seu local de moradia as dificuldades de ir à rua. Esse segmento parece exemplificar uma possibilidade colocada por Barry et al. (2001) de que os médicos procuram abordar o mundo da vida quando suspeitam que os sintomas apresentados por seus pacientes têm sua origem em uma desordem psicológica e não em uma lesão orgânica. A resposta usual dos pacientes nesses casos é uma negação da voz do mundo da vida, em favor da voz da medicina. Não é que tal possibilidade se aplique aqui diretamente, pois José tem lesões orgânicas que podem justificar seus sintomas físicos, mas o fato é que quando se trata especificamente desse comportamento - evitar sair de casa - a médica busca uma explicação psicológica sem, entretanto, encontrar colaboração do paciente para sustentar tal hipótese, pois ele insiste em formular suas queixas em termos corporais.

Diferente de Roqueline, que para psicologizar ou simplesmente para não cortar a voz do paciente, acaba dando muito espaço ao seu mundo da vida, Dr. Vivaldo, um dos preceptores, procura encaminhar a consulta em outra direção. Primeiro, ele prefere "evitar especulações" sobre as causas das múltiplas queixas de paciente. Além disso, quando interroga José, as cenas do cotidiano do paciente só são trazidas à baila para que o médico avalie o esforço que ele despendia em momento de dor cardíaca. Assim as cenas descritas por José, que poderiam oferecer contextos em que os problemas eram situados e entendidos, serviam apenas para avaliar a quantidade de esforço necessária para desencadear a dor.

Dr. Vivaldo: Qual foi o último dia que você teve dor?

José Antônio: Ontem, ontem eu tive duas vezes.

Dr. Vivaldo: Teve que botar Isordil embaixo da língua?

José Antônio: $\mathrm{E}$ aí quando eu estou com a dor eu boto um e outro Isordil, né?

Dr. Vivaldo: Cê, cê teve esse/essa dor fazendo o quê?

José Antônio: Essa dor é porque às vezes eu...

Dr. Vivaldo: Não! Vá, ontem especificamente cê teve dor fazendo o quê?

José Antônio: Ontem. Foi lavando os pano, esfregando os pano. E aí a dor apresentou, de eu ficar assim com a mão e parar.

Dr. Vivaldo: Que tipo de pano? Roupa pesada?

José Antônio: É uma camisa porque é eu tenho um menino que não trabalha e termina eu tendo que me ocupar, "pai lava a minha camisa" e eu "meu filho sua camisa é grossa seu pai não pode esfregar", aí termina eu lavando, né?

Dr. Vivaldo: Vamos fazer um, pedir um cateterismo pra ele pra gente ver a anatomia coronária dele, certo? 
Nas perguntas que faz, Dr. Vivaldo deixa pouco espaço para que José conte a sua história. Às primeiras tentativas do paciente expor um relato mais pessoal, ele interrompe e retoma aquilo que o interessa, avaliar o esforço físico e sua relação com a dor. Ao final, a insistência de José em colocar sua história consegue ultrapassar a barreira posta pelo médico, mas ainda assim isso de nada repercute na fala posterior de Dr. Vivaldo, que encerra a conversa recomendando a realização de um cateterismo. Depois, na discussão de caso com Roqueline, ele afirma que é preciso ter exames prontos antes da formulação de qualquer hipótese diagnóstica. Além disso, propõe que o paciente seja encaminhado para outros médicos (neurologista e angiologista) para que se estabeleça se suas queixas têm "algum substrato". Essas diferenças de condução do caso entre 0 preceptor e a estudante revelam que a medicina longe de ser uma prática homogênea, comporta modulações e distinções. Os médicos trazem para o encontro clínico diferentes níveis de treinamento, configurações de conhecimento e técnica, bem como projetam identidades distintas e possuem níveis diferenciados de investimento em sua prática cotidiana (FERZACCA, 2000).

Entretanto, a despeito das diferenças, médicos e estudantes parecem concordar - e o caso de José Antônio por romper com o padrão revela esse pressuposto - que o que se pode esperar de um paciente esclarecido sobre a doença e tratamento é que adote um tipo racional de conduta e cumpra com as determinações estabelecidas. Quando isso não acontece, surge uma demanda por explicação, é preciso que elementos outros sejam agregados aos dados usualmente fornecidos sobre o paciente (dados relativos a doença em um sentido biológico). Assim, os médicos constroem uma narrativa complementar -aprimorada ao longo do tempo - que justifica e torna plausível a ação imprópria do paciente (MATTINGLY, 1998). A concepção de sujeito que subjaz à medicina se desvela aqui: a do indivíduo racional, responsável, autônomo, que tem controle sobre suas ações. Como nessa concepção o social tem muito pouco a dizer sobre os indivíduos - o social para os médicos se restringe à escassez de recursos para aquisição de medicamentos ou alimentos corretos - a explicação para o caso só pode ser encontrada em um fator de ordem psicológica. Nessas situações várias suposições sobre o mundo do paciente são colocadas, para além dos dados que constam usualmente na construção do raciocínio clínico: relações familiares, sentimentos e motivos entram em cena para permitir aos médicos lidar com o que há de incerto nesse caso.

Se ouvimos a história na perspectiva do paciente, vemos que ele está ciente de que sua negligência com relação aos cuidados que deveria ter consigo são sujeitos a uma avaliação moral por parte dos médicos, por isso depois de um período de abandono do tratamento, ele se sente constrangido de voltar ao hospital. Diz ele na entrevista: 
José Antônio: Foi o seguinte: eu estava em casa, já sofrendo as dores, já com dores, mas como meu cartão tava velho em 93 , eu sou muito meigo, eu acho chato quando alguma pessoa me chama a atenção, me reclama (E: Hum hum.) eu procuro andar certo, como eu tinha o errado por ter abandonado, eu aí ficava com receio de vim do hospital e ter algum problema sério, (E: Hum hum.) por causa da ausência de dois anos e tanto.

Isso não significa dizer que aquilo que é suposto pelo médico acerca do paciente seja apropriado para descrever sua experiência, nem que esgotem as explicações possíveis para seus comportamentos. A história narrada por José em entrevista, em certa medida, corrobora a imagem que os médicos constroem dele, uma pessoa solitária, carente. Mas também se afasta em muitos aspectos das projeções que os médicos fazem acerca dele.

Ele fala de uma vida que é, desde o início, repleta de sofrimentos, doenças e carências que para serem supridas dependiam da solidariedade de estranhos, padrão que ele reproduz na relação com os médicos, aos quais ele sempre implica na sua história ao solicitar compaixão, doações, favores:

José Antônio: Eu comecei a vida também sempre sozinho lutando, que mãe eu num conheci. Então fui criado com esse sergipano, vim conhecer meu pai depois de dezoito anos, que também não encontrei apoio, e só vivia assim através de donativos, as pessoas me ajudando, pra tirar documentos, e... e... e... levando a vida sempre nesta base, através de donativos de ajuda pelos outros, dependendo sempre de alguém, nunca conseguia vencer a vida sozinho, lutando muito.

Há pontos de encontro entre o relato que José Antônio tece sobre si e a história forjada pelos médicos, mas há também desencontros. Um dos pontos dissonantes diz respeito ao modo como nas narrativas complementares a negligência para com 0 tratamento é pensada - atribuída a motivos psicológicos - e a versão de José sobre esse ponto. Para entendermos o ponto de divergência, precisaremos entrar em um tema que não é em nenhum momento problematizado pelos médicos: o tipo de conhecimento e as concepções de José acerca de seu problema. Se supõe que ele vê a enfermidade de um modo não muito distinto da concepção biomédica. A diligência da médica no início da consulta com a explicação sobre uso de medicamentos e seu estilo didático tem mais a ver com um esforço persuasivo do que informativo. Para os médicos o abandono e 0 desleixo com o tratamento decorre do desejo de chamar a atenção da família. $\mathrm{Na}$ entrevista, contudo, José revela tomar uma série de cuidados consigo que compreende a utilização de recursos outros que não aqueles estabelecidos pela medicina. Por exemplo, ele diz que não abandonou a insulina, mas simplesmente usou insulina em folha ao 
invés da injetável, o problema é que essa insulina, apesar de muito boa, não funcionou para ele. Além disso, ele desenvolveu uma teoria sobre a diabetes e como controlá-la equilibrando a ingestão de alimentos doces e amargos. Se a diabetes é caracterizada pelo excesso de açúcar no sangue, seria necessário para compensá-la a ingestão de alimentos amargos e azedos como jiló e limão.

Essa concepção que tem um peso para suas ações não é conhecida pelos médicos, nem encontra lugar na consulta. Quando se traz para dentro da consulta o mundo do paciente - e nesse caso há muito mais do que o usual - certamente alguns aspectos são julgados mais relevantes, enquanto outros ficam em uma zona de sombra e/ou são ativamente ignorados. Mas o que fica claro aí é que a noção doença e de cuidado consigo pode ter para os participantes sentidos bem distintos, que trazem um potencial de conflito - ainda que latente - para a relação do médico com o paciente, como acentua Freidson (1970), ao criticar a visão harmônica de Parsons dessa mesma relação.

Por fim, o caso de José Antônio nos revela também como um paciente descrito em um prontuário emerge de forma bem diferente quando sua história é narrada de modo pessoal. Não são apenas os fatos, as descrições ou estilo que diferem, mas o modo de relatar uma vida, como lembra Mattingly (1998), transforma o objeto clínico em um problema a ser resolvido. 0 raciocínio clínico se torna um raciocínio narrativo. Quando os médico contam uma história trazem para dentro da medicina dimensões da existência que de outro modo estariam banidas do discurso canônico. Entre os médicos e o paciente há, portanto, uma relação mais ativa e recíproca do que supõe o modo mais comum de descrever a prática clínica.

\section{ConClusão}

0 caso de José Antônio em sua estranheza pode nos dizer várias coisas sobre a prática médica e nos permite uma retomada de certos pontos anunciados antes quando apresentamos algumas questões relativas à literatura sobre o tema. Primeiro, seria possível interpretar a medicina como um empreendimento voltado para a sujeição e enquadramento do paciente a determinações produzidas pela ciência biomédica. De fato, há no caso, um empenho por parte dos médicos de normatização da conduta do paciente, eles se esforçam em conduzir a atitude de José Antônio para algo mais próximo ao padrão desejável de comportamento, o que implica em fazê-lo ter uma atitude mais vigilante para com seu corpo e uma aderência maior ao tratamento. Isso é feito como a abordagem foucaultiana aponta, não só através de proibições e castigos, mas também através de estratégias de persuasão, de aliciamento e gratificação. 
Acontece que a subordinação desse paciente insubordinado não seria possível sem que a própria discussão médica do caso e a consulta se deixassem impregnar pela história trazida por José. Aqui a voz do mundo da vida e a voz da medicina não estão simplesmente em conflito, mas por vezes têm que se entrelaçar. A personalidade do paciente, suas relações familiares, suas condições de vida irrompem na cena médica e não há como ignorar completamente isso. É claro que essa história dele não entra em sua totalidade, há aspectos ignorados e negligenciados, como aqueles relativos a suas concepções de doença e tratamento, justamente um dos tópicos que revelaria um conflito latente entre o saber médico e do paciente. Ainda assim José Antônio é em grande medida bem sucedido em expor questões relativas a seu mundo para médicos, mesmo para aqueles que não aceitam isso de bom grado.

0 fato de que médicos sejam mais ou menos porosos aquilo que vem do paciente nos lança na questão das modulações da prática médica. Vimos na consulta alguém que mostra uma inclinação maior a psicologizar o paciente e que por isso se abre mais a sua narrativa cotidiana, embora não necessariamente no sentido pretendido por ele, enquanto outro se filia a corrente majoritária na medicina que tende a fixar-se na questão biológica. Mas, em qualquer dos casos, podemos ver que a medicina nunca é puro emprego de conhecimento científico e técnico, e mesmo quando ela pretende ser, há sempre um horizonte mais amplo cercando a aplicação e sua prática. Assim como 0 paciente traz seu mundo da vida para a consulta (embora limitado, negado, ou negligenciado), há também uma série de concepções não explícitas que estão operando quando o médico atua profissionalmente, que ficam evidenciadas nos casos de quebra com o padrão esperado, que são justamente aqueles que suscitam uma compreensão mais elaborada do médico acerca do paciente. Nesse caso, há o suposto de que o paciente deve assumir os cuidados consigo e se não o faz é preciso encontrar uma explicação que dê conta dessa evasão para com suas obrigações. Essa noção de indivíduo racional e responsável é algo que a medicina carrega em si de modo implícito e que dá testemunho de seus vínculos com a cultura. Além disso, os especialistas recorrem em graus variados, ao acervo de conhecimentos genéricos acerca do funcionamento da realidade cotidiana para levar a cabo suas atividades profissionais. 0 saber do especialista, portanto, nunca substitui plenamente a experiência prática e social, mas quanto mais isso acontece 0 que se ganha não é um mundo melhor, mas uma perda de flexibilidade no trato com 0 mundo (GADAMER, 1996).

Afirmar a existência desse conhecimento da vida cotidiana e dos valores implícitos operando na medicina, entretanto, não implica, como crê Mishler, abrir mão de qualquer possibilidade de crítica. 0 problema é o rumo que essa crítica ou 
indignação por vezes toma: uma demanda para que o médico deixe de lado seus julgamentos. Mas não é porque faz julgamentos que o médico também pode ser sensível e solidário? 0 fato de que, na medicina, ciência, técnica e razão prática estejam imbricadas, ao invés de ser um obstáculo ao bom desempenho profissional, ao contrário, é o que permite que se encontre saídas para as situações mais difíceis, pois abre a possibilidade de diálogo entre duas formas de conceber a saúde e doença que se fundam em pressupostos distintos.

\section{REFERÊNCIAS}

ACIOLE, Giovanni Gurgel. 0 lugar, a teoria e a prática do profissional médico: elementos para uma abordagem crítica da relação médico paciente no consultório. Interface - Comunicação, Saúde e Educação, v. 8, n. 14, p. 95-112, 2004.

ARMSTRONG, D. The system of professions: an essay on the division of expert labor. Chicago: University of Chicago, 1977.

BARRY, C. A.; STEVENSON, F. A.; BRITTEN, N.; BARBER, N.; BRADLEY, C. P. Giving Voice to the Lifeworld. More Humane, more Effective Medical Care? a qualitative study of doctor-patient communication in general practice. Social Science and Medicine, v. 53, n.4, p. 487-505, 2001.

BOLTANSKI, Luc. As classes sociais e o corpo. Rio de Janeiro: Edições Graal, 1989.

BONET, Octavio. Saber e sentir: uma etnografia da aprendizagem da biomedicina. Rio de Janeiro: Fiocruz, 2004.

CAPRARA, Andrea; LINS E SILVA, Anamélia. A relação médico-paciente: para uma humanização da prática médica. Cadernos de Saúde Pública, v. 15, p. 1-17, 1999.

FERNANDES, João Cláudio Lara. A quem interessa a relação médico-paciente? Cadernos de Saúde Pública, v. 9, n.1, p. 21-27, jan./mar. 1993.

FERZACCA, Steve. Actually, I don't feel that bad: managing diabetes and the clinical encounter. Medical Anthropology Quaterly, v. 14, n.1, p. 28-50, 2000.

FOUCAULT, Michel. O Nascimento da Clínica. Rio de Janeiro: Forense Universitária, 1987.

FREIDSON, Eliot. Profession of medicine. New York: Dodd, 1970.

GADAMER, Hans George. El estado oculto de la salud. Barcelona: Gedisa, 1996. 
GOULART, Lúcia M. H. Figueiredo. Depois que forma, muda: estudo da relação médico-paciente no âmbito-da prática docente-assistencial na Faculdade de Medicina - UFMG. In: PAIVA, A.; SOARES, M. (Org.). Universidade, cultura e conbecimento: a educação pesquisa a UFMG. Belo Horizonte: Autêntica, 1998.

KOIFMAN, Lílian. 0 modelo biomédico e a reformulação do currículo médico da Universidade Federal Fluminense. História, Ciências, Saúde - Manguinhos, v. 8, n. 1, p. 48-70, 2001.

MARTINS, André. Biopolítica: 0 poder médico e a autonomia do paciente em uma nova concepção de saúde. Interface - Comunicação, Saúde, Educação, v. 8, n. 14, p. 21-32, 2004.

MARTINS, Paulo Henrique. Contra a desumanização da medicina: crítica sociológica das práticas médicas modernas. Petrópolis: Vozes, 2003.

MATTINGLY, Cheryl. In search of the good: narrative reasoning e clinical practice. Medical Antbropology Quarterly, v. 12, n. 3, p. 273-297, 1998.

MENEZES, Rachel Aisengart. Etnografia do Ensino Médico em CTI. Interface - Comunicação, Saúde, Educação, v. 5, n. 9, p. 117-130, 2001.

MERHY, Emerson Elias. Um ensaio sobre o médico e suas valises tecnológicas. Interface Comunicação, Saúde, Educação, v. 4, n. 6, p. 109-116, 2000.

MISHLER, Elliot. The Discourse of Medicine. Norwood, New Jersey: Ablex, 1984.

PARSONS, Talcott. Some theoretical considerations bearing on the field of medical sociology. In: Social structure and personality. New York: The Free Press. 1965.

SCHERER, Magda Duarte dos Anjos; MARINO, Selma Regina Andrade; RAMOS, Flávia Regina Souza. Rupturas e resoluções no modelo de atenção à saúde: reflexões sobre a estratégia saúde da família com base nas categorias kuhnianas. Interface - Comunicação, Saúde, Educação, v. 9 , n. 16, p. 53-66, 2005.

SCHREIBER, Lilia Blima. No encontro da técnica com a ética: o exercício de julgar e decidir no cotidiano do trabalho em Medicina. Interface - Comunicação, Sauide, Educação, v. 1, n. 1, p. 123-140, 1997.

SCHUTZ, Alfred. Fenomenologia e relações sociais. Rio de Janeiro: Zahar, 1979.

WAITZKIN, Howard. The politics of medical encounters: how patients and doctors deal with social problems. New Haven: Yale University Press, 1991. 